\title{
Effectiveness of Different Cellulose-Based Filtration Materials against Inhalation of SARS-CoV-2-Like Particles
}

\author{
Alyne R. de Araújo ${ }^{1}{ }^{\circledR}$, Lívio C. C. Nunes ${ }^{2}$, Karla C. B. F. Oliveira ${ }^{2}{ }^{\circledR}$, Maria G. F. M. Carvalho ${ }^{2}$, \\ Juliana C. Cardoso ${ }^{3}$, Patricia Severino ${ }^{3,4}{ }^{-}$, Monica F. L. R. Soares ${ }^{5}$, Eliana B. Souto ${ }^{6,7, *}$ and Gildário D. Lima ${ }^{1, *}$ \\ 1 Biotechnology and Biodiversity Center Research, Biotec, Federal University of Delta of Parnaíba, \\ Parnaíba 64202-020, PI, Brazil; alyne_biomed@hotmail.com \\ 2 Department of Pharmacy, Federal University of Piauí, Teresina 60400-000, PI, Brazil; \\ liviocesar@hotmail.com (L.C.C.N.); karlacostab@yahoo.com.br (K.C.B.F.O.); \\ mgfmedeiros@hotmail.com (M.G.F.M.C.) \\ 3 Industrial Biotechnology Program, University of Tiradentes, Aracaju 49010-390, SE, Brazil; \\ juaracaju@yahoo.com.br (J.C.C.); pattypharma@gmail.com (P.S.) \\ 4 Tiradentes Institute, $150 \mathrm{Mt}$ Vernon St, Dorchester, MA 02125, USA \\ 5 Department of Pharmacy, Federal University of Pernambuco, Recife 50741-000, PE, Brazil; \\ monica.soares@ufpe.br \\ 6 Faculty of Pharmacy, University of Coimbra, 3000-548 Coimbra, Portugal \\ 7 CEB-Centre of Biological Engineering, University of Minho, 4710-057 Braga, Portugal \\ * Correspondence: ebsouto@ff.uc.pt (E.B.S.); gildario@ufpi.edu.br (G.D.L.)
}

Citation: Araújo, A.R.d.; Nunes, L.C.C.; Oliveira, K.C.B.F.; Carvalho, M.G.F.M.; Cardoso, J.C.; Severino, P.; Soares, M.F.L.R.; Souto, E.B.; Lima, G.D. Effectiveness of Different Cellulose-Based Filtration Materials against Inhalation of SARS-CoV-2-Like Particles. Nanomanufacturing 2021, 1, 57-66. https://doi.org/10.3390/ nanomanufacturing1020006

Academic Editor:

Andres Castellanos-Gomez

Received: 1 February 2021

Accepted: 17 May 2021

Published: 1 July 2021

Publisher's Note: MDPI stays neutral with regard to jurisdictional claims in published maps and institutional affiliations.

Copyright: (c) 2021 by the authors. Licensee MDPI, Basel, Switzerland. This article is an open access article distributed under the terms and conditions of the Creative Commons Attribution (CC BY) license (https:/ / creativecommons.org/licenses/by/ $4.0 /)$.

\begin{abstract}
The respiratory protection equipment (RPE) used by health professionals consists of an essential device to prevent infectious diseases, especially those caused by biological agents such as the coronavirus (SARS-CoV-2). The current epidemiological panorama is worrying, and the context of creation and production of the mask has emerged as an alternative to RPE to face the public health crisis worldwide. The aim of this work is to present a low-cost alternative as an FFP2-like filter for a reusable respirator face mask. This study presents the comparison of different cellulose-based filtering materials performed by retention testing, time saturation testing, aerosol penetration testing, nanoparticle $(\sim 140 \mathrm{~nm})$ filtration testing, bacterial filtration efficiency (BFE), analysis of material morphology and usability. The reusable respirator face mask used in this study is an open-source innovation, using 3D printing. Cotton disc proved to be the best filter material for the reusable mask, with satisfactory results and a performance similar to that shown by the N95-type mask. The cotton disc ensured effectiveness over $6 \mathrm{~h}$ of use, and after that, the reusable respirator face mask (here, Delfi-TRON ${ }^{\circledR}$ ) needed to be sanitized and replenished with a new cotton disc. Upon preliminary analyses of filtration efficiency, the selected filter was shown to be a low-cost biodegradable and biocompatible alternative.
\end{abstract}

Keywords: respiratory protection equipment; respirator face mask; reusable mask; filter material; FFP2-like filter; health professionals

\section{Introduction}

The respiratory protection equipment (RPE) used by healthcare workers consists of an essential device to prevent infectious diseases, especially those caused by biological agents such as the coronavirus (SARS-CoV-2) [1,2]. The use of RPE is a standard practice and is based on the idea of creating a physical barrier close to the nose and mouth, thus preventing the spread of viral particles by infected people and protecting the healthy population [3]. Therefore, in times of pandemic, the use of masks by health workers and by infected people must be widely promoted, in order to mitigate community transmission and the dissemination of the biological agent in question [4].

The coronavirus disease (COVID-19) is a viral respiratory infection transmitted from human to human who, after close contact, spread viral particles when breathing, talking, 
coughing or sneezing via droplets and aerosols [5]. This infection has been recognized as a pandemic and has led to a shortage of and increased demand for some medical devices, especially RPE [6]. Respiratory and facial protection are necessary for microorganisms that are usually transmitted via the airborne route or via droplets and require filtration of inhaled contaminated air [7]. A respirator or filtering face piece (FFP) is one type of personal protective equipment (PPE), mainly used by health professionals (especially during aerosol-generating procedures); it is designed to protect people from exposure to airborne contaminants and is considered a core component of protection [8,9]. According to Tcharkhtchi et al. [10], mask filtration is based on different mechanisms consisting of gravity sedimentation, inertial impaction, interception, diffusion, and electrostatic attraction.

The current epidemiological panorama is worrying, and the context shows the need to create and produce masks as alternative RPE, as well as easily accessible and low-cost filters, to face the public health crisis worldwide [10]. The aim of this work is to study a biodegradable, biocompatible and low-cost alternative such as the cotton disc, to be used as an FFP2-like filter for a reusable respirator face mask. The mask used was Delfi-TRON ${ }^{\circledR}$ face mask (Figure 1), an open-source innovation using 3D printing, which was made by $\mathrm{TRON}^{\circledR}$, an Educational Robotics Startup (https: / tron-edu.com/mascara/, accessed on 1 February 2021).

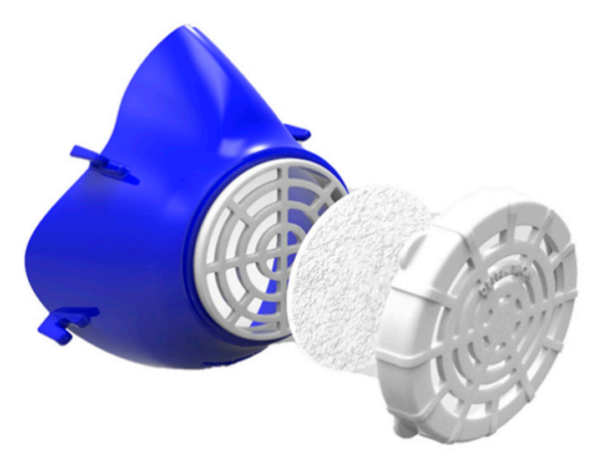

Figure 1. Scheme of reusable respirator face mask with cotton disc as filter element.

\section{Materials and Methods}

\subsection{Filter Tested Materials}

The filters studied for use in the Delfi-TRON ${ }^{\circledR}$ reusable respirator face mask were based on commercially accessible materials, which were low-cost, renewable and easily acquired by hospitals and healthcare workers. All the chosen materials were made of cellulose, such as qualitative filter paper $\left(80 \mathrm{~g} / \mathrm{m}^{2}\right)$, cotton discs $\left(100 \%\right.$ cotton, $\left.180 \mathrm{~g} / \mathrm{m}^{2}\right)$ and coffee filters $\left(100 \mathrm{~g} / \mathrm{m}^{2}\right)$. Surgical face masks (approximately $20 \mathrm{~g} / \mathrm{m}^{2}$ in a single layer) and N95 respirator face masks $\left(150 \mathrm{~g} / \mathrm{m}^{2}\right)$ were used to control the tests. Because of the thickness variations, different brands were tested for cotton discs. All analyses were performed in replicates. The tests were performed according to the Brazilian National Health Surveillance Agency (ANVISA) RDC No. 356 [11], based on technical standards of ABNT NBR 13698:2011 [12] and ABNT NBR 13697:2010 [13] for FPP, level 2; N95 or equivalent.

\subsection{Filter Characterization}

\subsubsection{Retention Test, Time Saturation Test and Aerosol Penetration Test}

Briefly, the tests were performed with saline solution $(0.9 \% \mathrm{NaCl} w / v)$ aerosol from nebulization, to evaluate the percentage of $\mathrm{NaCl}$ (Sodium chloride P.A, Neon, Suzano, SP, Brazil), retained by the selected materials and the time taken for the filters to be saturated with moisture, similar to what would happen with the air exhaled by the user reaching the filter material. Retention testing with a continuous flow of $40 \mathrm{~mL} / \mathrm{min}$ was carried out using a single or double layer of alternating suggested materials. For the aerosol, penetration (\%) testing was carried out by loading the filter with $150 \mathrm{mg}$ of $\mathrm{NaCl}(0.9 \%)$ 
polydispersed aerosol (particles in the size range 50-700 nm) under continuous airflow for $2 \mathrm{~min}$. A sample of $5.5 \mathrm{~cm}$ diameter was used to evaluate particle retention, saturation, and penetration. The results were obtained using ion-selective electrode (ISE) equipment (Electrolyte Analyzer, AVL, Roche, New York, NY, USA) [14].

\subsubsection{Nanoparticle Filtration Test}

Filters were tested using previously characterized silver nanoparticles (AgNPs) with a $\sim 140 \mathrm{~nm}$ mean size, the approximate size of Sars-CoV-2 (with an average size of $125 \mathrm{~nm}$ ) [15] and a concentration of $19.10 \times 10^{9} \pm 7.42 \times 10^{8}$ particles $/ \mathrm{mL}$ by nanoparticle tracking analysis (NTA) on Malvern NanoSight NS300 equipment (Malvern Instruments, Malvern, UK), using a $542 \mathrm{~nm}$ LASER module and NTA 3.2 software (Malvern Instruments, Malvern, UK) [16]. The test consisted of spraying AgNPs on the filter until saturation. The filters with the retained nanoparticles and the solution that passed through each filter were evaluated by UV-vis spectroscopy (Shimadzu, Kyoto, Japan) in the wavelength range 200 to $500 \mathrm{~nm}$. To analyze the nanoparticles that were retained, each filter was left in contact with distilled water for $2 \mathrm{~min}$ submerged in $4 \mathrm{~mL}$ of water under constant magnetic stirring. The graphics were created in OriginPro 8.5 software (Northampton, MA, USA).

\subsubsection{Study of Filter Morphology}

The morphology of all filters was assessed using optical microscopy (Zeiss, Berlin, Germany) of the materials, with a magnitude of $40 \times$.

\subsubsection{Bacterial Filtration Efficiency (BFE)}

The bacterial filtration efficiency (BFE) testing was performed only for the candidate filter suitable for the reusable respirator face mask and according to the EN 14683:2019 and the AC:2019 standards [17]. Briefly, the selected filter was clamped between the petri dish containing the culture medium (Tryptic Soy Agar-TSA, BD Difco ${ }^{\mathrm{TM}}$, Franklin Lakes, NJ, USA) and the aerosol source of Staphylococcus aureus ATCC 25923, at a concentration of $5 \times 10^{5} \mathrm{CFU} / \mathrm{mL}$. The same procedure was performed without the filter material as a control for bacterial growth on the agar. For the test, S. aureus strain was previously cultivated on TSA agar for $24 \mathrm{~h} / 35 \pm 2{ }^{\circ} \mathrm{C}$ and the aerosol was prepared from the strain inoculation in $0.9 \%$ sterile saline until reaching an absorbance ranging from 0.08 to 0.13 at $625 \mathrm{~nm}\left(5 \times 10^{5} \mathrm{CFU} / \mathrm{mL}\right)$, following CLSI standards (CLSI, 2015) [18]. The bacterial filtration efficiency (BFE) of the selected filter was observed after $24 \mathrm{~h}$ under the same conditions mentioned above, and was given by the number of colony-forming units (CFUs) passing through the tested filter expressed as a percentage of the number of CFUs present in the challenge aerosol (growth control). The test was performed in duplicate.

\subsubsection{Filter Time-of-Use}

Filter time-of-use testing was performed only for the candidate filter suitable for reusable respirator face masks, i.e., the cotton disc. The testing was carried out by conditioning the respiratory protection equipment (RPE) on a bench simulating the behavior of the face mask when used by the user (air at $37^{\circ} \mathrm{C}$ and saturated with moisture). Briefly, the conditioning of RPE to simulate the use was performed in a mannequin with openings for entry and exit of the saturated air, simulating 25 expiration and inspiration cycles, according to ABNT NBR 13698:2011 [12]. After this period, aerosol penetration testing, nanoparticle filtration testing and bacterial filtration efficiency (BFE) of the selected masks were repeated, according to the above.

\subsubsection{Filter Usage Time}

Filter usage-time testing was performed only for the candidate filter suitable for reusable respirator face masks, i.e., the cotton disc. The testing was carried out by conditioning the Delfi-TRON ${ }^{\circledR}$ respiratory protection equipment (RPE) with the cotton disc (Figure 1) on a bench, simulating the behavior of the face mask when used by the user (air 
at $37^{\circ} \mathrm{C}$ and saturated with moisture). Briefly, the conditioning of RPE to simulate the use was performed in a mannequin with openings for entry and exit of the saturated air, simulating 25 expiration and inspiration cycles, according to ABNT NBR 13698:2011 [12]. After this period, aerosol penetration testing, nanoparticle filtration testing and bacterial filtration efficiency (BFE) of the selected masks were repeated, according to the above.

\section{Results and Discussion}

Several methodologies have been described for the retention, and saturation test results are depicted in Table 1 . The retention showed values of $99.0 \%, 96.0 \%, 98.6 \%, 78.0 \%$ and $98.5 \%$ for the qualitative paper filter, cotton disc, coffee filter, surgical mask and N95 respirator, respectively. The saturation test showed that the period of time of alternative materials (paper filter, cotton disc, coffee filter) was shorter compared to the surgical mask and N95 respirator. For comparison, we also studied bilayer filters, such as qualitative filter paper and cotton disc, showing a result of $99.5 \%$ for total retention, being superior to isolated materials and commercial masks, this result was already expected according to the literature, which shows that increasing the number of layers in the masks improves their performance [19].

Table 1. Percentage of $\mathrm{NaCl}$ solution retention that passes through the filter layer for the time necessary to saturate the filter with water vapor.

\begin{tabular}{ccc}
\hline Material & Total Retention (\%) & Time of Saturation (s) \\
\hline Qualitative paper filter & 99.0 & 16.0 \\
Cotton disc & 96.0 & 17.0 \\
Coffee filter & 98.6 & 7.0 \\
Surgical mask & 78.0 & 45.0 \\
N95 respirator & 98.5 & 70.0 \\
\hline
\end{tabular}

The results of retention and time saturation were attributed to different hydrophobicity and hydrophilicity characteristics of each material. The results show that aerosol penetration was less than 1\% for the cotton disc and N95 respirator, which is in agreement with the certification required for the N95 facepiece. However, the surgical mask was not an efficient barrier, which corroborates the findings by Coia et al. [7], who claim that the surgical face mask, despite being an efficient physical barrier against larger droplets, cannot retain aerosols efficiently. Zangmeister et al. [20] also used N95 respirators and surgical masks in their tests to evaluate the filtration efficiency of alternative materials, reporting results similar to those described by us.

Cotton discs, qualitative filter paper and coffee filters are easily found materials, consisting of cellulose, which is the most abundant polymer on Earth and represents one of the largest sources of renewable raw materials [21]. The similar constitution may justify the similar percentage of $\mathrm{NaCl}$ solution retention; despite that, the materials have a difference in the fiber weave (which can be seen in the microscopic analyses), in the thickness (qualitative filter paper $=180 \mu \mathrm{m}$, coffee filter $=215 \mu \mathrm{m}$, cotton disc $=400 \mu \mathrm{m}$ ) and in the pore size (qualitative filter paper $=11 \mu \mathrm{m}$, coffee filter $\cong 20 \mu \mathrm{m}$, cotton disc $\cong 136 \mu \mathrm{m}$ ). The saturation time of the N95 respirator was longer than the time observed for the tested materials, possibly due to the overlap of materials of different thicknesses and, in some cases, it has charged fibers. The obtained result is in line with expectations, considering that the N95 respirator is certified according to the National Institute for Occupational Safety and Health (NIOSH) regulations [22,23]; however, the literature also reports that these masks have increased airflow resistance and, in some cases, low facial adhesion [24]. The findings by Bałazy et al. [23] showed a percentage of $\mathrm{NaCl}$ aerosol penetration similar to those we described for the $\mathrm{N} 95$ respirator $(\sim 1 \%)$, with a flow rate of $30 \mathrm{~L} / \mathrm{min}$. In addition, they demonstrated that this percentage can vary according to the flow and particle diameter. The authors used a wide-range particle spectrometer (WPS) with a differential mobility analyzer (DMA), condensation particle counter (CPC) and laser particle spectrometer (LPS) 
for measurements. Another methodology that can be used for the $\mathrm{NaCl}$ aerosol penetration test is the TSI 3160 Fractional Efficiency Tester (TSI 3160) equipped with a long DMA (TSI 3081) [25].

Viral particles that cause respiratory diseases are very hazardous, being among the smallest bioaerosol agents, with particle sizes up to $300 \mathrm{~nm}$ [24]. With respect to silver nanoparticle $(\sim 140 \mathrm{~nm})$ retention, the cotton disc and N95 mask were capable of retaining a more significant amount of nanoparticles, with the silver nanoparticles that passed through the materials being practically undetectable (Figure 2A,B). Despite the limitations of the technique used, which does not allow calculation of the exact number of particles that were retained or that passed through the analyzed filters, the potential of these filters to retain the nanoparticles used can be clearly observed. Figure 2 shows a similar behavior between the N95 mask (Figure 2B) and the cotton disc (Figure 2A) in relation to the ability to retain the silver nanoparticles.
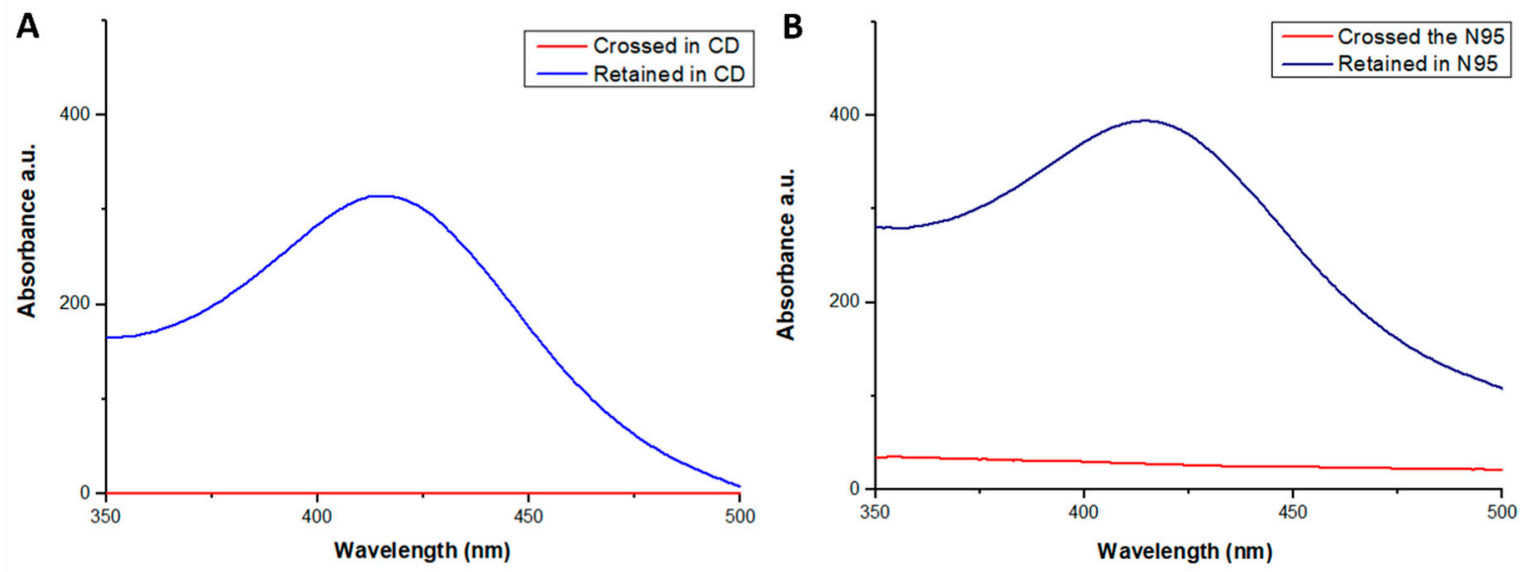

Figure 2. UV-vis scanning spectra obtained from samples of cotton disc-CD (A) and N95 mask (B).

Additionally, in the spectrum of the qualitative filter paper, a small resonance band was recorded in the region of $415 \mathrm{~nm}$, which represents the nanoparticles that passed through the qualitative filter paper. The nanoparticles that were retained in this material did not appear in the spectrum as they were firmly absorbed inside the material (Figure 3A,B). This finding would be expected because the literature reports the use of cellulose filter paper with retained silver nanoparticles for antibacterial applications [26]. The reported phenomenon can be attributed to the deposition of nanoparticles on the filter surface, which may be due to the formation of particulate aggregates.

A

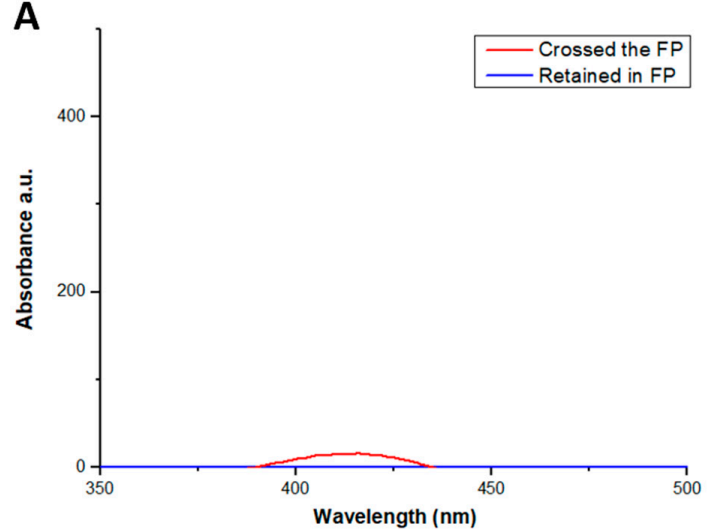

\section{B}

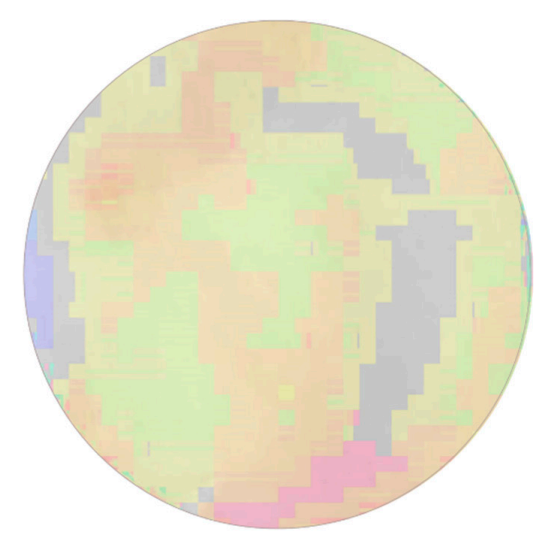

Figure 3. (A) UV-vis spectra of test with qualitative filter paper (FP). Black line: AgNPs retained in qualitative filter paper; red line: AgNPs that crossed the qualitative filter paper. (B) Image of the filter paper impregnated with silver nanoparticles (which has a characteristic color, yellow). 
However, surgical masks allowed a greater passage of nanoparticles of mean size $140 \mathrm{~nm}$ (Figure 4), a fact that can be attributed to the larger and irregular pores that the masks present (see morphology).

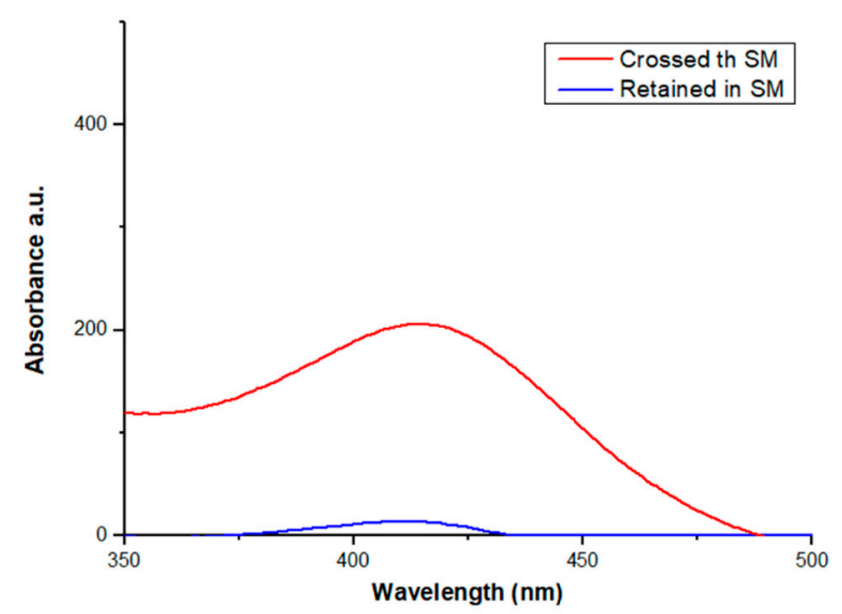

Figure 4. Absorption spectra in the ultraviolet region for the sample retained (black line) in the surgical mask (SM) and the sample that passed through it (red line).

Silver nanoparticles have several biomedical applications, including for wound healing [27] and as antimicrobials [28]. Here, silver nanoparticles were used because they are a similar size to the coronavirus, which has a diameter between 60 and $140 \mathrm{~nm}$. Silver nanoparticles have already been used for testing the filtration potential of filtering facepiece respirators; however, the authors used a scanning mobility particle sizer (SMPS; TSI model 3080) equipped with a nanodifferential mobility analyzer (Nano-DMA, TSI model 3085) or an ultrafine condensation particle counter (UCPC; TSI 3025A) for measurements [25].

The images depicted in Figure 5 show the microscopic (upper panels) and macroscopic (lower panels) appearance of the used materials. The cotton disc (Figure 5A) has sparse fibers, similar to the cotton fibers described by Chen et al. [29] at the same magnitude but, due to the various layers, the presence of large pores could not be seen in more detail. The morphology of the coffee filter (Figure 5B) showed a predominance of full cellulose fibers [30], and the pores are easily observed. However, the qualitative filter paper (Figure 5C) presents thinner cellulose fibers [30] and, apparently, in a higher number, allowing a narrower web to be obtained. Finally, the conventional surgical mask (Figure 5D) reveals a more standardized weave with fine fibers, but with larger and more numerous pores amongst the materials tested in this work, the intertwined and visible fibers, as well as the open spaces, are also shown in the findings of Neupane et al. [31] and Kumar et al. [32]. The N95 respirator (Figure 5E) has sparse fibers in the visualized layer [32], which are slightly less sparse than the fibers of the cotton disc, but again because of the various layers, pores could not be observed in detail.

The microscopic image of the surgical mask (Figure 5D) shows a low density of fibers in relation to other samples, which explains the low filtration of the nanoparticles used (Figure 4). A similar finding was demonstrated by Kähler and Hain [33] for Halyard H600 material (used in the USA for protecting healthcare workers from aerosol infection), which was not able to protect people in an environment contaminated by SARS-CoV-2. 


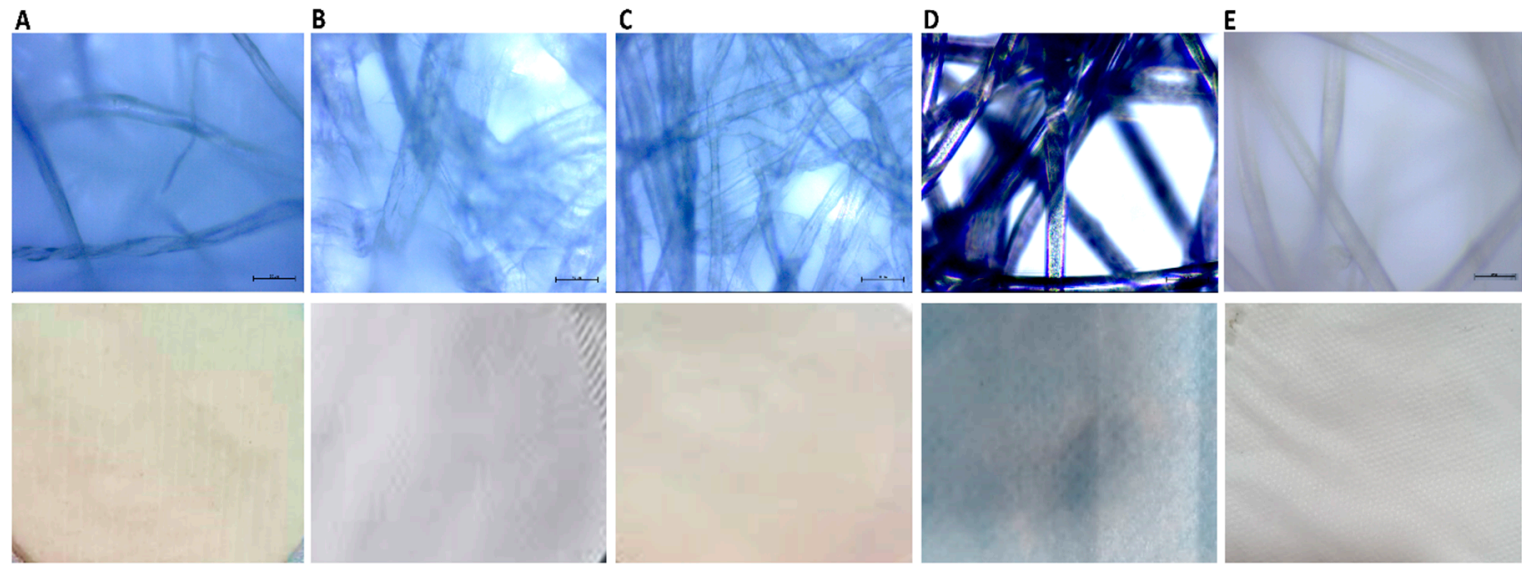

Figure 5. Morphology of used materials. Optical microscopy with $40 \times$ magnitude (upper panels) and macroscopic images (lower panels). Cotton disc (A), coffee paper filter (B), quantitative filter paper (C), conventional surgical mask (D), and N95 mask (E), morphologically identified using optical microscopy with $40 \times$ magnitude. Bar $=50 \mu \mathrm{m}$.

With respect to the bacterial filtration capacity (aerosol with mean diameter of $\sim 3 \mu \mathrm{m}$ ), the face masks specified in EN 14683:2019 and in AC:2019 standards [17] are classified into two types (Type I and Type II) according to bacterial filtration efficiency (BFE). Type I could filter $\geq 95 \%$ while type II could filter $\geq 98 \%$ of the bacteria present in the aerosol tested. The cotton disc showed BFE $\geq 98 \%$, being able to prevent the passage of the bacteria used in the study according to the recommendations. In Figure 6 it is possible to observe the characteristic colonies of Staphylococcus aureus (Gram-positive bacteria of spherical shape) grown on the agar on the plates that did not have the filter material between them and the aerosol source. In contrast to the test plates, the placing of the cotton disc between the strain and the aerosol source compromised the growth of bacterial colonies on the agar, confirming the effectiveness of this type of mask. The literature reports that the filtering mechanism of bacteria follows the same mechanism of capture of other particles, therefore, the filtration efficiency for bacteria would be positively correlated with the result for other particles [34].

The composition of Delfi-TRON ${ }^{\circledR}$ is based on polylactic acid (PLA) and polyurethane (TPU) from renewable sources (corn, wheat, rice) that are commonly employed in 3D printing. According to Jayaweera et al. [5], respirators composed of elastomers may be considered as alternatives to the disposable N95 respirator, mainly for healthcare workers, considering the similar capacity for filtering viruses, such as SARS-CoV-2. In addition, the authors cite the potential for reuse (after cleaning) as one of the main advantages of elastomeric respirators. The results of filter time-of-use did not show significant statistical differences in relation to the unused cotton filter and after $12 \mathrm{~h}$ of simulation of use, as previously described. Always aiming at safety, it was decided to standardize the time of use of the cotton disc filter to half the time, i.e., $6 \mathrm{~h}$, since there may be variations among the cotton disc manufacturers that were not considered in our study. It is worth mentioning that in order to define the frequency of safe exchange of EPR, the type of pathogen, the time of exposure and the characteristics of the environment must be considered. We did not find any significant differences between the different brands of cotton disc used, because the thickness variation between brands was very small. 

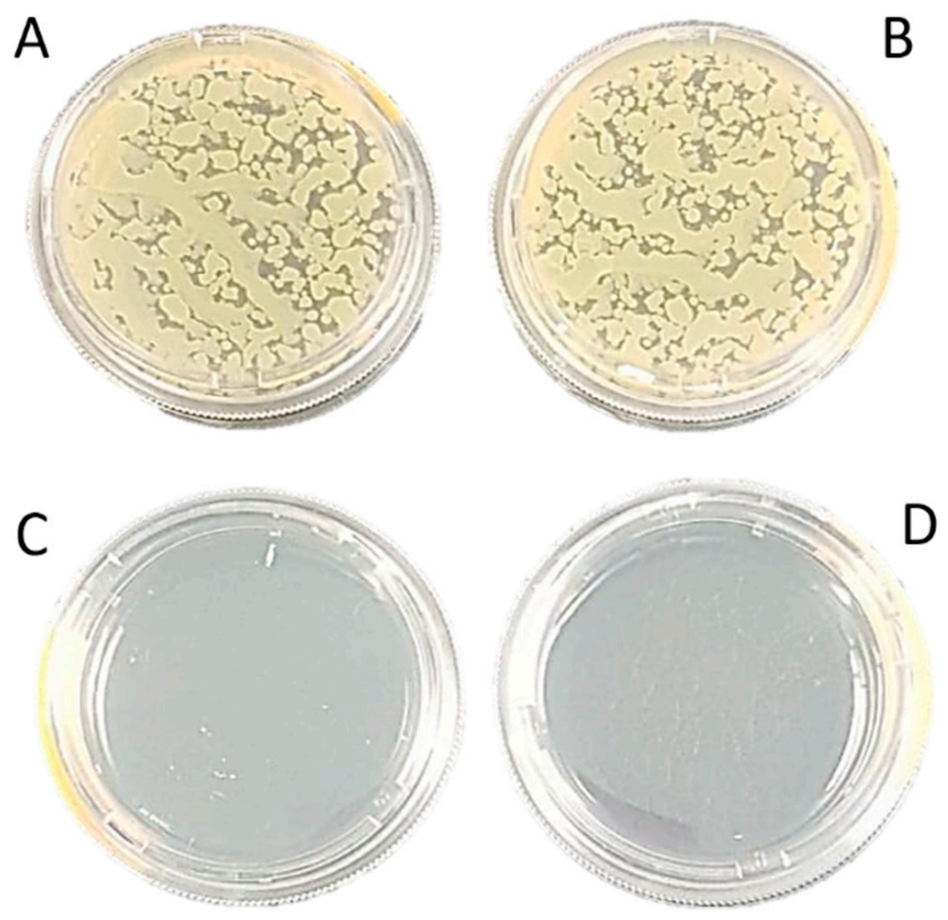

Figure 6. Bacterial filtration efficiency test without $(\mathbf{A}, \mathbf{B})$ and with $(\mathbf{C}, \mathbf{D})$ cotton disc as filter, where it is possible to observe the growth of Staphylococcus aureus colonies in the test without the cotton disc $(\mathbf{A}, \mathbf{B})$ and absence in the test with the cotton disc $(\mathbf{C}, \mathbf{D})$.

\section{Conclusions}

From the obtained results, among the tested samples, the cotton disc was shown to be the best filter material for the reusable Delfi-TRON ${ }^{\circledR}$ mask, with satisfactory results and a similar performance to that shown by the N95-type mask. The cotton disc was found to be efficient for both nanoparticle filtration (resembling the coronavirus in size) and bacterial strain. This work is the first study in which different cellulose-based filtering materials have been compared with respect to their performance in respect of their capacity for retention, time for saturation, aerosol penetration, nanoparticle filtration, bacterial filtration, material morphology and usability. Our preliminary findings support the added value of the cotton disc alternative; thus, further studies are needed in order to complement and validate the outcomes reported in this study.

Author Contributions: Conceptualization, A.R.d.A., L.C.C.N., K.C.B.F.O., M.G.F.M.C., J.C.C., M.F.L.R.S., G.D.L.; formal analysis, methodology, investigation, A.R.d.A., L.C.C.N., K.C.B.F.O., M.G.F.M.C., J.C.C., P.S., M.F.L.R.S., E.B.S., G.D.L.; resources, supervision, visualization, J.C.C., P.S., M.F.L.R.S., E.B.S., G.D.L.; writing一original draft, A.R.d.A., L.C.C.N., K.C.B.F.O., M.G.F.M.C.; writing-review and editing, M.F.L.R.S., E.B.S., G.D.L. All authors have read and agreed to the published version of the manuscript.

Funding: This research received no external funding.

Institutional Review Board Statement: Not applicable.

Informed Consent Statement: Not applicable.

Data Availability Statement: Not applicable.

Acknowledgments: TRON ${ }^{\circledR}$ Educational Robotics Startup and Social Service of Commerce (Sesc PI/MG) and the Federation of Industries of Piauí (FIEPI) for institutional support.

Conflicts of Interest: The authors declare no conflict of interest. 


\section{References}

1. $\quad$ Lancet, T. COVID-19: Protecting health-care workers. Lancet 2020, 395, 922. [CrossRef]

2. Bourrous, S.; Barrault, M.; Mocho, V.; Poirier, S.; Ouf, F.-X.; Bardin-Monnier, N.; Charvet, A.; Thomas, D.; Bescond, A.; Fouqueau, A.; et al. A Performance Evaluation and Inter-laboratory Comparison of Community Face Coverings Media in the Context of COVID-19 Pandemic. Aerosol Air Qual. Res. 2021, 21. [CrossRef]

3. Cook, T.M. Personal protective equipment during the COVID-19 pandemic-A narrative review. Anaesthesia 2020. [CrossRef]

4. Fathizadeh, H.; Maroufi, P.; Momen-Heravi, M.; Dao, S.; Köse, Ş.; Ganbarov, K.; Pagliano, P.; Esposito, S.; Kafil, H.S. Protection and disinfection policies against SARS-CoV-2 (COVID-19). Infez. Med. 2020, 28, 185-191.

5. Jayaweera, M.; Perera, H.; Gunawardana, B.; Manatunge, J. Transmission of COVID-19 virus by droplets and aerosols: A critical review on the unresolved dichotomy. Environ. Res. 2020, 188, 109819. [CrossRef] [PubMed]

6. Bauchner, H.; Fontanarosa, P.B.; Livingston, E.H. Conserving Supply of Personal Protective Equipment-A Call for Ideas. JAMA 2020, 323, 1911. [CrossRef] [PubMed]

7. Coia, J.E.; Ritchie, L.; Adisesh, A.; Makison Booth, C.; Bradley, C.; Bunyan, D.; Carson, G.; Fry, C.; Hoffman, P.; Jenkins, D.; et al. Guidance on the use of respiratory and facial protection equipment. J. Hosp. Infect. 2013, 85, 170-182. [CrossRef] [PubMed]

8. Park, S.H. Personal Protective Equipment for Healthcare Workers during the COVID-19 Pandemic. Infect. Chemother. 2020, 52, 165-182. [CrossRef] [PubMed]

9. European Centre for Disease Prevention and Control. Using Face Masks in the Community; European Union: Stockholm, Sweden, 2020.

10. Balachandar, V.; Mahalaxmi, I.; Kaavya, J.; Vivekanandhan, G.; Ajithkumar, S.; Arul, N.; Singaravelu, G.; Senthil Kumar, N.; Mohana Dev, S. COVID-19: Emerging protective measures. Eur. Rev. Med. Pharmacol. Sci. 2020, 24, 3422-3425. [CrossRef]

11. ANVISA. Resolução da Diretoria Colegiada (RDC) 356/2020. Available online: http:/ / portal.anvisa.gov.br (accessed on 17 February 2021).

12. Associação Brazileira de Normas Técnicas. Respiratory Protective Devices—Filtering Half Mask to Protect against Particles (ABNT NBR 13698:2011); Technical Norm, Zambini Institute; Associação Brazileira de Normas Técnicas: Rio de Janeiro, Brazil, 2011; ISBN 978-85-07-02692-1.

13. Associação Brazileira de Normas Técnicas. Respiratory Protective Devices_Particle Filters (ABNT NBR 13697:2010); Technical Norm, Zambini Institute; Associação Brazileira de Normas Técnicas: Rio de Janeiro, Brazil, 2010; ISBN 978-85-07-02230-5.

14. Lim, H.-R.; Kim, Y.-S.; Kwon, S.; Mahmood, M.; Kwon, Y.-T.; Lee, Y.; Lee, S.M.; Yeo, W.-H. Wireless, Flexible, Ion-Selective Electrode System for Selective and Repeatable Detection of Sodium. Sensors 2020, 20, 3297. [CrossRef]

15. Zhu, N.; Zhang, D.; Wang, W.; Li, X.; Yang, B.; Song, J.; Zhao, X.; Huang, B.; Shi, W.; Lu, R.; et al. A Novel Coronavirus from Patients with Pneumonia in China, 2019. N. Engl. J. Med. 2020, 382, 727-733. [CrossRef] [PubMed]

16. de Araujo, A.R.; Ramos-Jesus, J.; de Oliveira, T.M.; de Carvalho, A.M.A.; Nunes, P.H.M.; Daboit, T.C.; Carvalho, A.P.; Barroso, M.F.; de Almeida, M.P.; Plácido, A.; et al. Identification of Eschweilenol C in derivative of Terminalia fagifolia Mart. and green synthesis of bioactive and biocompatible silver nanoparticles. Ind. Crops Prod. 2019, 137, 52-65. [CrossRef]

17. UNE-EN 14683:2019+AC:2019. Medical Face Masks—Requirements and Test Methods; UNE—Normalización Española: Madrid, Spain, 2019.

18. Clinical Laboratory Standards Institute (CLSI). Methods for Dilution Antimicrobial Susceptibility Test for Bacteria That Grow Aerobically. Approved Standard M07-A10; CLSI: Wayne, PA, USA, 2015.

19. Konda, A.; Prakash, A.; Moss, G.A.; Schmoldt, M.; Grant, G.D.; Guha, S. Aerosol Filtration Efficiency of Common Fabrics Used in Respiratory Cloth Masks. ACS Nano 2020, 14, 6339-6347. [CrossRef]

20. Zangmeister, C.D.; Radney, J.G.; Vicenzi, E.P.; Weaver, J.L. Filtration Efficiencies of Nanoscale Aerosol by Cloth Mask Materials Used to Slow the Spread of SARS-CoV-2. ACS Nano 2020, 14, 9188-9200. [CrossRef]

21. Thakur, V.K.; Thakur, M.K. Processing and characterization of natural cellulose fibers/thermoset polymer composites. Carbohydr. Polym. 2014, 109, 102-117. [CrossRef]

22. Wang, J.; Tronville, P. Toward standardized test methods to determine the effectiveness of filtration media against airborne nanoparticles. J. Nanopart. Res. 2014, 16, 2417. [CrossRef]

23. Balazy, A.; Toivola, M.; Reponen, T.; Podgórski, A.; Zimmer, A.; Grinshpun, S.A. Manikin-based performance evaluation of N95 filtering-facepiece respirators challenged with nanoparticles. Ann. Occup. Hyg. 2006, 50, 259-269. [CrossRef] [PubMed]

24. Tiliket, G.; Sage, D.L.; Moules, V.; Rosa-Calatrava, M.; Lina, B.; Valleton, J.M.; Nguyen, Q.T.; Lebrun, L. A new material for airborne virus filtration. Chem. Eng. J. 2011, 173, 341-351. [CrossRef]

25. Rengasamy, S.; Eimer, B.C.; Shaffer, R.E. Comparison of nanoparticle filtration performance of NIOSH-approved and CE-marked particulate filtering facepiece respirators. Ann. Occup. Hyg. 2009, 53, 117-128. [CrossRef]

26. Praveena, S.M.; Han, L.S.; Than, L.T.L.; Aris, A.Z. Preparation and characterisation of silver nanoparticle coated on cellulose paper: Evaluation of their potential as antibacterial water filter. J. Exp. Nanosci. 2016, 11, 1307-1319. [CrossRef]

27. Diniz, F.R.; Maia, R.C.A.P.; Rannier, L.; Andrade, L.N.; Chaud, M.V.; da Silva, C.F.; Corrêa, C.B.; de Albuquerque Junior, R.L.C.; da Costa, L.P.; Souto, E.B.; et al. Silver nanoparticles-composing alginate/gelatin hydrogel improves wound healing in vivo. Nanomaterials 2020, 10, 390. [CrossRef] 
28. Sánchez-López, E.; Gomes, D.; Esteruelas, G.; Bonilla, L.; Lopez-Machado, A.L.; Galindo, R.; Cano, A.; Espina, M.; Ettcheto, M.; Camins, A.; et al. Metal-Based Nanoparticles as Antimicrobial Agents: An Overview. Nanomaterials 2020, 10, 292. [CrossRef] [PubMed]

29. Chen, W.; Abe, K.; Uetani, K.; Yu, H.; Liu, Y.; Yano, H. Individual cotton cellulose nanofibers: Pretreatment and fibrillation technique. Cellulose 2014, 21, 1517-1528. [CrossRef]

30. Imai, M.; Furujo, A.; Sugiyama, J. Direct observation of cellulase penetration in oven-dried pulp by confocal laser scanning microscopy. Cellulose 2019, 26, 7653-7662. [CrossRef]

31. Neupane, B.B.; Mainali, S.; Sharma, A.; Giri, B. Optical microscopic study of surface morphology and filtering efficiency of face masks. PeerJ 2019, 7, e7142. [CrossRef]

32. Kumar, A.; Sangeetha, D.N.; Yuvaraj, R.; Menaka, M.; Subramanian, V.; Venkatraman, B. Quantitative Performance Analysis of Respiratory Facemasks Using Atmospheric and Laboratory Generated Aerosols Following with Gamma Sterilization. Aerosol Air Qual. Res. 2021, 21, 200349. [CrossRef]

33. Kähler, C.J.; Hain, R. Fundamental protective mechanisms of face masks against droplet infections. J. Aerosol Sci. 2020, 148, 105617. [CrossRef]

34. Jung, S.; An, J.; Na, H.; Kim, J. Surface Energy of Filtration Media Influencing the Filtration Performance against Solid Particles, Oily Aerosol, and Bacterial Aerosol. Polymers 2019, 11, 935. [CrossRef] 